\title{
Copper(II) complexes with aroylhydrazones
}

\author{
SAMUDRANIL PAL \\ School of Chemistry, University of Hyderabad, Hyderabad 500 046, India \\ e-mail: spsc@uohyd.ernet.in
}

\begin{abstract}
The coordination chemistry of copper(II) with tridentate aroylhydrazones is briefly discussed in this article. Two types of aroylhydrazones derived from aroylhydrazines and ortho-hydroxy aldehydes or 2-pyridine-carboxaldehyde have been used. The characterization of the complexes has been performed with the help of various physico-chemical techniques. Solid state structural patterns have been established by X-ray crystallography. In the solid state, structural varieties of these complexes are seen to range from monomeric, dimeric, polymeric and onedimensional self-assembly via hydrogen bonds and $\pi-\pi$ interactions. EPR spectroscopy and variable temperature magnetic susceptibility measurements have been used to reveal the nature of the coordination geometry and magnetic characteristics of these complexes.
\end{abstract}

Keywords. Copper(II) complexes; aroylhydrazones; crystal structures; intermolecular interactions; self-assembly; magnetic properties; imine to imidate transformation.

\section{Introduction}

Dinuclear copper complexes are receiving continuous attention primarily due to their structural, magnetic, electron transfer and catalytic properties ${ }^{1}$ and as models for metalloenzymes containing dicopper active sites ${ }^{2}$. Tridentate Schiff bases are very effective in producing dinuclear species of metal ions such as copper(II) that prefer square-planar or square-pyramidal geometry. In addition, such ligands can be used to obtain mononuclear hexacoordinated copper(II) complexes that are of considerable interest from the standpoint of their coordination geometry and spectroscopic properties. Aroylhydrazones of ortho-hydroxy aldehydes (I) contain two dissociable protons at the amide and phenol functionalities. In deprotonated state these ligands provide a phenolate$\mathrm{O}$, an imine- $\mathrm{N}$ and a deprotonated amide-O as metal-coordinating centres. On the other hand, deprotonated aroylhydrazones of 2-pyridine-carboxaldehyde (II) provide a pyridine- $\mathrm{N}$, an imine- $\mathrm{N}$ and a deprotonated amide- $\mathrm{O}$ as metal-coordinating centres. We are interested in these Schiff bases to obtain amide-O coordinated higher-valent complexes and amide-O bridged dinuclear species. Such complexes are very attractive<smiles>O=C(N/N=C/c1cc(P)ccc1O)c1ccc(Br)cc1</smiles>

(I)<smiles>O=C(N/N=C/c1ccccn1)c1ccc(Br)cc1</smiles>

(II) 
for studying the effect of amide protonation state on the coordination geometry, molecular structure, redox properties and interaction between the metal ions ${ }^{3}$. In the following account, the results obtained in our study on copper(II) chemistry with these two types of aroylhydrazones are summarized.

\section{Bisphenoxo bridged dicopper(II) complex}

In a dicopper(II) complex with I, either the phenolate-O or the deprotonated amide-O can bridge the metal ions. In such a situation, it has been observed earlier that the most negatively charged centre acts as the bridging atom ${ }^{4}$. Although dinuclear copper(II) complexes with this type of aroylhydrazones are reported earlier ${ }^{5}$, the identity of the bridging atom in these complexes is not unambiguous. We have been successful in growing single crystals of a dicopper(II) complex with $\mathrm{H}_{2}$ bhsNO $\mathrm{N}_{2}$ having the molecular<smiles>O=C(N/N=C/c1cc([N+](=O)[O-])ccc1O)c1ccccc1</smiles>

formula $\left.\left[\mathrm{Cu}_{2}(\text { bhsNO})_{2}\right)_{2}\left(\mathrm{H}_{2} \mathrm{O}\right)_{2}\right]^{6}$. The complex has been synthesized by the reaction of $\mathrm{Cu}\left(\mathrm{O}_{2} \mathrm{CCH}_{3}\right)_{2} \cdot \mathrm{H}_{2} \mathrm{O}$ and $\mathrm{H}_{2}$ bhsNO $\mathrm{N}_{2}(1: 1$ mole ratio) in methanol. The molecular structure of the complex is shown in figure 1 . In solid state, the molecule has a crystallographically imposed inversion symmetry. The copper(II) centres are square-pyramidal. The amide-O, the imine- $\mathrm{N}$ and the bridging phenolate- $\mathrm{O}$ centres constitute the square bases and the apical sites are occupied by $\mathrm{O}$-atoms of two water molecules.

Cryomagnetic measurements indicate that an antiferromagnetic interaction is operative between the two metal centres in $\left[\mathrm{Cu}_{2}\left(\mathrm{bhsNO}_{2}\right)_{2}\left(\mathrm{H}_{2} \mathrm{O}\right)_{2}\right]$. The least-squares fit of the magnetic data using an expression ${ }^{7}$ derived from the isotropic spin Hamiltonian, $H=-$ $2 J S_{1} \cdot S_{2} \cdot\left(S_{1}=S_{2}=1 / 2\right)$ provided a value of $-186(5) \mathrm{cm}^{-1}$ for the coupling constant $J$. The values of $2 J$ observed for previously reported ${ }^{8}$ bisphenoxo bridged complexes are in the range -722 to $-857 \mathrm{~cm}^{-1}$. In such dicopper(II) complexes, the extent of antiferromagnetic interaction is known to decrease primarily due to: (i) decrease in the $\mathrm{Cu}-\mathrm{O}-\mathrm{Cu}$ bridge

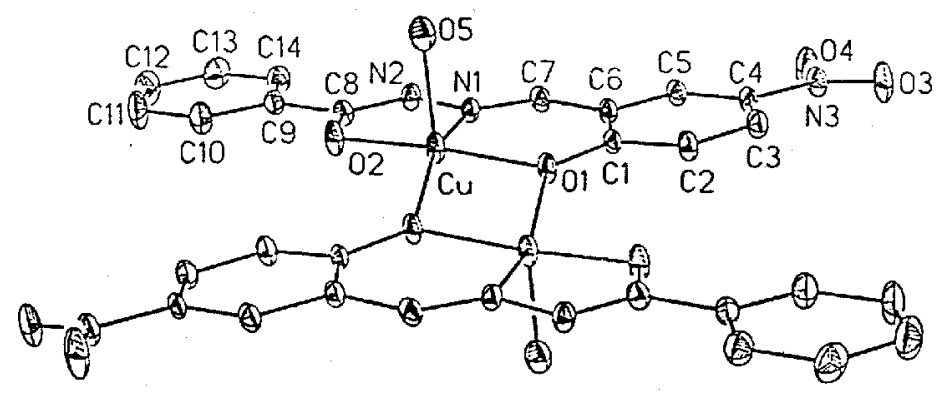

Figure 1. Molecular structure of $\left.\left[\mathrm{Cu}_{2}(\text { bhsNO})_{2}\right)_{2}\left(\mathrm{H}_{2} \mathrm{O}\right)_{2}\right]$. Hydrogen atoms are omitted for clarity. 
angle, (ii) increase in the pyramidal character of the bridging $\mathrm{O}$-atom, and (iii) tetrahedral distortion of the square base containing the metal centre ${ }^{8}$. In $\left[\mathrm{Cu}_{2}\left(\mathrm{bhsNO}_{2}\right)_{2}\left(\mathrm{H}_{2} \mathrm{O}\right)_{2}\right]$, the bridging phenolate-O atoms are planar (solid angle $359 \cdot 6^{\circ}$ ). However, the $\mathrm{Cu}$ atom is displaced by $0.24 \AA$ from the mean basal plane towards the apical water O-atom. In addition, the average deviation of $\mathrm{O} 1$ and $\mathrm{O} 2$ from the mean basal plane is $0 \cdot 11 \AA$ and that of $\mathrm{N} 1$ and symmetry related phenolate-O is $-0 \cdot 11 \AA$. Thus the lowering of the $J$ value in the present complex compared to that of the other similar species is possibly due to the distortion of the coordination geometry around the metal centre, relatively smaller $\mathrm{Cu}-\mathrm{O}-\mathrm{Cu}$ bridge angle $\left(100 \cdot 4^{\circ}\right)$ and the presence of electron withdrawing nitro group ${ }^{9}$ at the para position of the bridging phenolate-O.

\section{Protonation of the amide functionalities in $\left[\mathrm{Cu}_{2}\left(\mathrm{bhsNO}_{2}\right)_{2}\left(\mathrm{H}_{2} \mathrm{O}\right)_{2}\right]$}

To explore the effect of amide protonation state on the properties of $\left[\mathrm{Cu}_{2}\left(\mathrm{bhsNO}_{2}\right)_{2}\right.$ $\left(\mathrm{H}_{2} \mathrm{O}\right)_{2}$ ], we have tried to protonate the coordinated amide functionalities by adding stoichiometric quantity of $\mathrm{HClO}_{4}$ to the acetonitrile solution of the complex. In this attempt, a square-pyramidal monomeric copper(II) complex, $\left.\left[\mathrm{Cu}(\mathrm{HbhsNO})_{2}\right)\left(\mathrm{CH}_{3} \mathrm{CN}\right)_{2}\right]$ $\mathrm{ClO}_{4}$ has been isolated ${ }^{10}$. The solid state molecular structure of the complex has been determined by X-ray crystallography. The bond parameters associated with the metal ion and other physical properties are consistent with the +2 oxidation state of the metal ion. Intraligand bond parameters clearly suggest the protonation of the amide functionality. The mononegative planar ligand coordinates the metal ion via the phenolate- $\mathrm{O}$, the imine- $\mathrm{N}$ and the $\mathrm{O}$-atom of the protonated amide functionality. The $\mathrm{N}$-atom of one of the two acetonitrile molecules completes the square base and that of the other acetonitrile molecule satisfies the apical position (figure 2). The $\mathrm{Cu}$-atom is displaced by $0.23 \AA$ out of the mean basal plane in the direction of the apical acetonitrile $\mathrm{N}$-atom. The equatorial acetonitrile molecule is bound to the metal ion more strongly ( $\mathrm{Cu}-\mathrm{N} 4,1.946(3) \AA)$ compared to the apical acetonitrile in a reasonably linear fashion (Cu-N4-C15,

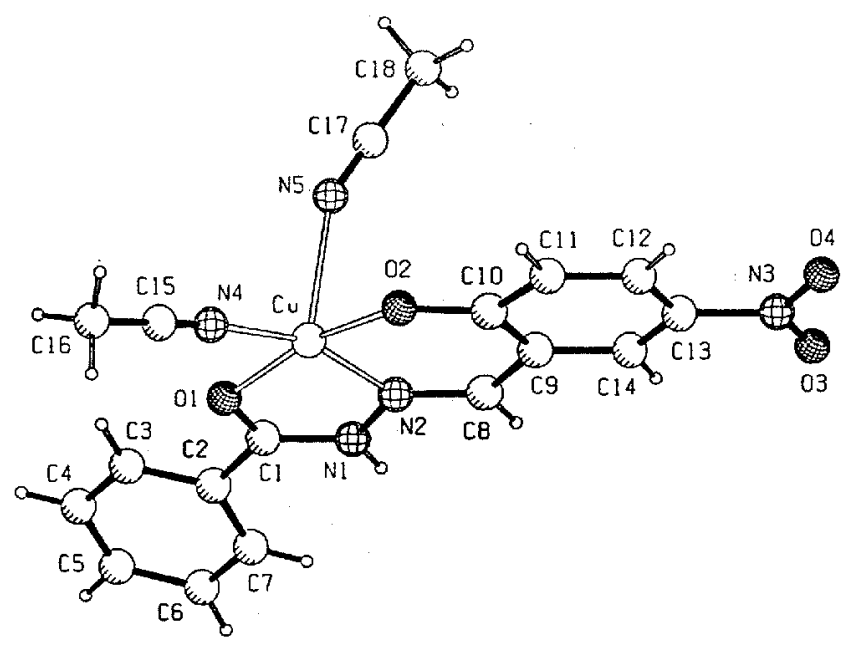

Figure 2. Structure of $\left[\mathrm{Cu}\left(\mathrm{HbhsNO}_{2}\right)\left(\mathrm{CH}_{3} \mathrm{CN}\right)_{2}\right]^{+}$and the atom labelling scheme. 
$\left.172 \cdot 9(3)^{\circ}\right)$. However, the apical acetonitrile molecule $(\mathrm{Cu}-\mathrm{N} 5,2 \cdot 387(3) \AA)$ is in a very rare bent mode $\left(\mathrm{Cu}-\mathrm{N} 5-\mathrm{C} 17,154 \cdot 6(3)^{\circ}\right)$. In structurally characterized adducts of nitriles ${ }^{11}$, the observed deviations of the $\mathrm{M}-\mathrm{N} \equiv \mathrm{C}$ bond angle from $180^{\circ}$ are within $8^{\circ}$ for mondentate nitriles and that for chelating dinitriles are within $11^{\circ}$. To the best of our knowledge, the only other known example containing a similar bent monodentate nitrile is $\mathrm{SmI}_{2}\left(\mathrm{NCCMe}_{3}\right)_{2}\left(\mathrm{Sm}-\mathrm{N} \equiv \mathrm{C}, 151 \cdot 3(6)^{\circ}\right)^{12}$.

In order to examine whether the copper(II) coordination geometry can be influenced by an electron releasing substituent on the aroyl fragment of the ligand, another Schiff base, viz. $\mathrm{H}_{2} \mathrm{mhsNO}_{2}$, has been used to synthesize a similar acetonitrile coordinated mono-<smiles>COc1ccc(C(=O)N/N=C/c2cc([N+](=O)[O-])ccc2O)cc1</smiles>

nuclear copper(II) complex. The molecular formula of the isolated complex is $\left[\mathrm{Cu}\left(\mathrm{HmhsNO}_{2}\right)\left(\mathrm{CH}_{3} \mathrm{CN}\right)\left(\mathrm{ClO}_{4}\right)\right]^{10}$. Figure 3 depicts the molecular structure of this complex determined by X-ray crystallography. The bond parameters and other physical properties suggest the presence of protonated amide functionality in $\mathrm{HmhsNO}_{2}{ }^{-}$and also the +2 oxidation state of the metal ion in this complex. The coordination geometry around the metal centre is again square-pyramidal. The tridentate O,N,O-donor ligand and the acetonitrile- $\mathrm{N}$ constitute the basal plane. However, in contrast to the previous complex a perchlorate $\mathrm{O}$-atom $(\mathrm{Cu}-\mathrm{O} 6,2 \cdot 564(2) \AA)$ occupies the apical position and there is no displacement $(0.007 \AA)$ of the metal centre towards apical coordinating atom. In this complex, the equatorial acetonitrile molecule (Cu-N4, 1.965(2) $\AA$; CurN4-C16, $\left.177 \cdot 6(2)^{\circ}\right)$ is unexceptional.

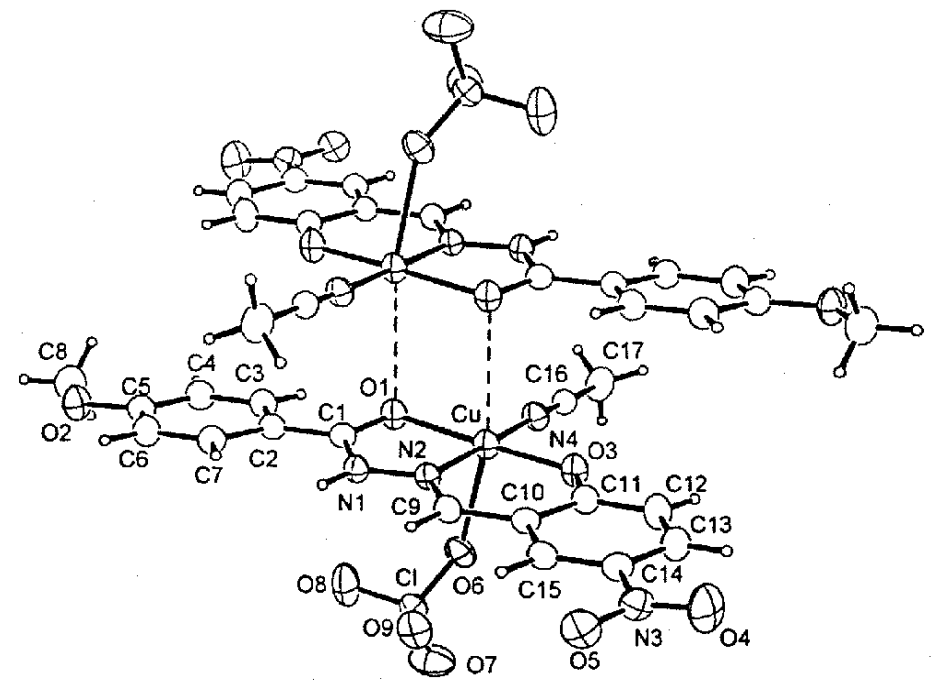

Figure 3. Molecular structure of $\left[\mathrm{Cu}\left(\mathrm{HmhsNO}_{2}\right)\left(\mathrm{CH}_{3} \mathrm{CN}\right)\left(\mathrm{ClO}_{4}\right)\right]$ and the dimeric arrangement of the molecules via weak $\mathrm{Cu} \cdots \mathrm{O}$ interactions. 
The shortest $\mathrm{Cu} \cdots \mathrm{Cu}$ distance in the crystal lattice of this molecule is $3 \cdot 835(1) \AA$. Interestingly this is due to formation of dimeric aggregates via the amide-O of the protonated amide functionilities. Two $\left[\mathrm{Cu}\left(\mathrm{HmhsNO}_{2}\right)\left(\mathrm{CH}_{3} \mathrm{CN}\right)\left(\mathrm{ClO}_{4}\right)\right]$ molecules are involved in a pair of complementary very weak interactions between the metal ions and the amide-O centres $\left(\mathrm{Cu}^{\prime} \cdots \mathrm{O} 1,2 \cdot 909(2) \AA\right.$, $\left.\mathrm{Cu}^{\prime} \cdots \mathrm{O} 1-\mathrm{Cu}, 101 \cdot 77(9)^{\circ}\right)$ at the sites trans to the apical perchlorate-O atom (figure 3 ). This weak interaction may be partially responsible for not observing the displacement of the $\mathrm{Cu}$-atom from the basal plane towards the perchlorate-O atom.

\section{Complexes with 2-pyridine-carboxaldehyde aroylhydrazones}

\subsection{Mononuclear hexacoordinated copper(II) complexes}

In hexacoordinated copper(II) complexes, tetragonal distortion from the octahedral symmetry due to the Jahn-Teller distortion is very common. Such complexes with different ligands are attractive mainly due to the variation in the coordination geometry and the spectral features ${ }^{13,14}$. Schiff bases (II) derived from 2-pyridine-carboxaldehyde and aroylhydrazines provide the pyridine- $\mathrm{N}$, the imine- $\mathrm{N}$ and the amide-O as the metal coordinating atoms and form two five-membered chelate rings upon complexation with a metal ion. Two of such deprotonated meridionally spanning ligands produce a neutral copper(II) complex containing a $\mathrm{CuN}_{4} \mathrm{O}_{2}$ coordination sphere. In methanolic media, reactions of one mole of $\mathrm{Cu}\left(\mathrm{O}_{2} \mathrm{CCH}_{3}\right)_{2} \cdot \mathrm{H}_{2} \mathrm{O}$ and two moles of HL (Hpabh, Hpamh<smiles>[R]c1ccc(C(=O)N/N=C/c2ccccn2)cc1</smiles>

Hpabh $(\mathrm{R}=\mathrm{H})$

$\operatorname{Hpamh}(\mathrm{R}=\mathrm{OMe})$

$\operatorname{Hpadh}\left(\mathrm{R}=\mathrm{NMe}_{2}\right)$

and Hpadh) in methanol afford the complexes of general formula $\mathrm{CuL}_{2}$ in moderate to high yield ${ }^{15}$. The $S=1 / 2$ spin state in each complex is confirmed by room temperature $(298 \mathrm{~K})$ magnetic moments $\left(1.90-2.08 \mu_{B}\right)$. The electronic spectral features are comparable with those of other similar hexacoordinated copper(II) complexes. X-ray crystal structure of $\left[\mathrm{Cu}(\mathrm{pabh})_{2}\right]$ has been determined (figure 4). Intraligand distances are in conformity with the enolate form of both the ligands. Interestingly the two ligands are inequivalent in terms of metal to coordinating atom distances. For the first ligand the distances are: $\mathrm{Cu}-\mathrm{N} 1,2 \cdot 130(3) \AA ; \mathrm{Cu}-\mathrm{N} 2,1.940(3) \AA ; \mathrm{Cu}-\mathrm{O} 1,2 \cdot 099(2) \AA$ and for the second ligand the distances are: $\mathrm{Cu}-\mathrm{N} 4,2.286(3) \AA$; $\mathrm{Cu}-\mathrm{N} 5,1.972(3) \AA$; $\mathrm{Cu}-\mathrm{O} 2,2 \cdot 294(3) \AA$. These distances clearly suggest a tetragonal elongation along the $\mathrm{O} 2-\mathrm{Cu}-\mathrm{N} 4$ axis. The average of $\mathrm{Cu}-\mathrm{N}(\mathrm{imine})$ distances is $1.956 \AA$ and that of $\mathrm{Cu}-\mathrm{O} 1$ and $\mathrm{Cu}-\mathrm{N} 1$ distances is $2 \cdot 114 \AA$. These two values indicate a tetragonal compression along the N2-Cu-N5 axis. Such a compression is not unexpected considering the rigidity of these tridentate ligands ${ }^{14}$. Thus the $\mathrm{CuN}_{4} \mathrm{O}_{2}$ coordination sphere in $\left[\mathrm{Cu}(\mathrm{pabh})_{2}\right]$ is rhombically distorted. This fact is further supported by the EPR results as described below.

Room temperature $(298 \mathrm{~K})$ powder EPR spectral profiles of all the three complexes (figure 5) display an interesting trend. Three signals observed for $\left[\mathrm{Cu}(\mathrm{pabh})_{2}\right]$ are in complete agreement with the rhombic distortion of the $\mathrm{CuN}_{4} \mathrm{O}_{2}$ coordination sphere as found in the solid state structure. At low temperature such rhombic spectra are reported 
for hexacoordinated copper(II) complexes of meridionally spanning tridentate ligands ${ }^{14}$. In the spectrum of $\left[\mathrm{Cu}(\mathrm{pamh})_{2}\right], g_{1}$ is observed as a shoulder on $g_{2}$ indicating lesser rhombicity of the $\mathrm{N}_{4} \mathrm{O}_{2}$ sphere compared to that in $\left[\mathrm{Cu}(\mathrm{pabh})_{2}\right]$. On the other hand, $\left[\mathrm{Cu}(\text { padh })_{2}\right]$ displays a broad asymmetric signal near $g=2$ (figure 5) indicating a

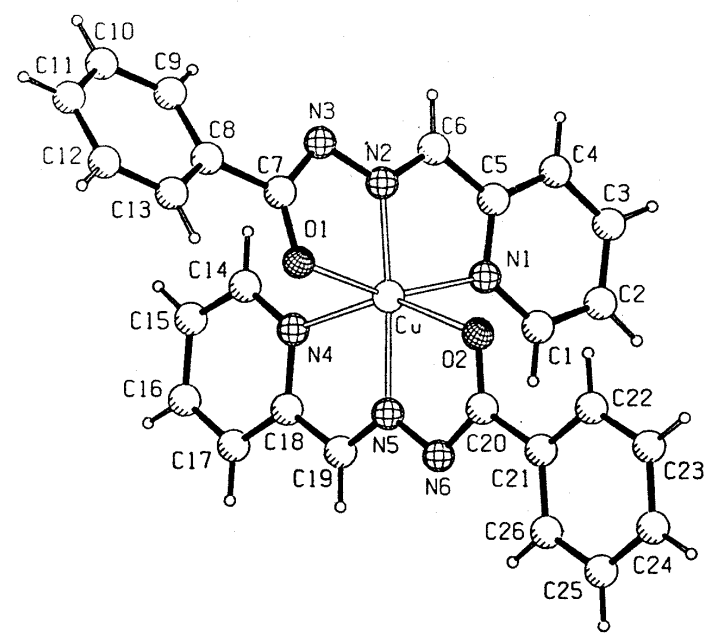

Figure 4. Molecular structure of $\left[\mathrm{Cu}(\mathrm{pabh})_{2}\right]$ with the atom labelling scheme.

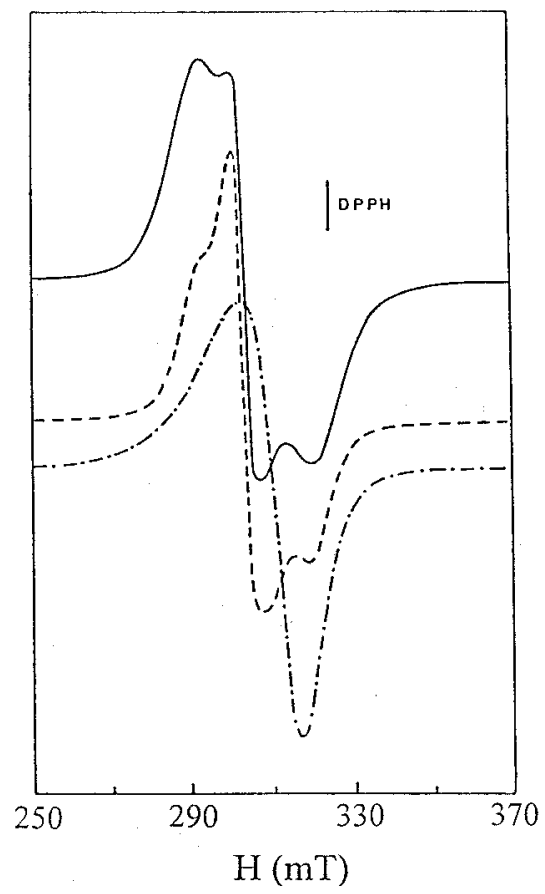

Figure 5. Powder EPR spectra (at $298 \mathrm{~K})$ of $\left[\mathrm{Cu}(\text { pabh })_{2}\right](-),\left[\mathrm{Cu}(\text { pamh })_{2}\right](-)$ and $\left[\mathrm{Cu}(\text { padh })_{2}\right](-\cdot-\cdot-)$. 
tetragonal elongation rather than a rhombic distortion. A possible rationale for this gradual transition from rhombic to tetragonally elongated $\mathrm{N}_{4} \mathrm{O}_{2}$ sphere around copper(II) in these complexes is as follows. In the structure of $\left[\mathrm{Cu}(\mathrm{pabh})_{2}\right]$, two ends of one ligand sit on the Jahn-Teller elongated axis. The imine-N of this ligand and the other three coordinating atoms of the second ligand constitute the square-plane. In this $\mathrm{N}_{\text {imine }} \mathrm{O}_{\text {amide }} \mathrm{N}_{\text {imine }} \mathrm{N}_{\text {pyridine }}$ square-plane the average of $\mathrm{Cu}-\mathrm{N}_{\text {imine }}$ bond distances is smaller than that of the $\mathrm{Cu}-\mathrm{N}_{\text {pyridine }}$ and $\mathrm{Cu}-\mathrm{O}_{\text {amide }}$ bond distances. The electron donating ability of the substituent at the para position of the aroyl fragment decreases in the order $\mathrm{padh}^{-}>$ pamh $^{-}>$pabh $^{-}$. Therefore the $\mathrm{Cu}-\mathrm{O}_{\text {amide }} \sigma$-bond strength is expected to decreases in the order $\left[\mathrm{Cu}(\text { padh })_{2}\right]>\left[\mathrm{Cu}(\text { pamh })_{2}\right]>\left[\mathrm{Cu}(\text { pabh })_{2}\right]$ and hence the $\mathrm{Cu}-\mathrm{O}_{\text {amide }}$ bond distance decreases in the reverse order. As a result, the difference between the average of the $\mathrm{Cu}-\mathrm{N}_{\text {imine }}$ bond distances and that of $\mathrm{Cu}-\mathrm{N}_{\text {pyridine }}$ and $\mathrm{Cu}-\mathrm{O}_{\text {amide }}$ bond distances decrease in the following order: $\left[\mathrm{Cu}(\text { pabh })_{2}\right]>\left[\mathrm{Cu}(\text { pamh })_{2}\right]>\left[\mathrm{Cu}(\text { padh })_{2}\right]$. Thus between $\left[\mathrm{Cu}(\text { pabh })_{2}\right]$ and $\left[\mathrm{Cu}(\text { pamh })_{2}\right]$, the former displays a larger rhombicity than the latter in the EPR spectrum. The near axial spectrum of $\left[\mathrm{Cu}(\text { padh })_{2}\right]$ indicates similar metal to coordinating atom distances in the $\mathrm{N}_{\text {imine }} \mathrm{O}_{\text {amide }} \mathrm{N}_{\text {imine }} \mathrm{N}_{\text {pyridine }}$ square-plane.

\subsection{Dimeric and polymeric copper(II) complexes}

The tridentate deprotonated Schiff bases of type II are expected to provide the O-atom of the amide functionality as the bridging atom in a dicopper(II) complex. In search of such a complex, we have used all the three Schiff bases (HL = Hpabh, Hpamh and Hpadh) described in the previous section. The observations for Hpadh are quite different from that for Hpabh and Hpamh. The results obtained with the latter two Schiff bases are described in this section.

In methanolic media, reactions of $\mathrm{Cu}\left(\mathrm{O}_{2} \mathrm{CCH}_{3}\right)_{2} \cdot \mathrm{H}_{2} \mathrm{O}$ and $\mathrm{HL}$ (in 1:1 mole ratio) afford complexes having empirical formulae $\mathrm{CuL}\left(\mathrm{O}_{2} \mathrm{CCH}_{3}\right)$ and that of $\mathrm{CuCl}_{2} \cdot 2 \mathrm{H}_{2} \mathrm{O}$, HL and $\mathrm{KOH}$ (in 1:1:1 mole ratio) provide complexes having empirical formulae $\mathrm{CuLCl}^{16}$. IR spectra of the complexes indicate deprotonation of the amide functionalty in HL. The powder EPR spectral profiles of the complexes are very similar and typical of a squareplanar or square-pyramidal copper(II) complex. The $g_{\|}$and $g_{\perp}$ values are observed in the ranges 2.26-2.33 and 2.09-2.19 respectively. Electronic spectral features of these complexes in methanol solutions are also consistent with a square-planar or squarepyramidal copper(II) complex. In methanol solutions, all the complexes are found to be redox active. Cyclic voltammograms of $\mathrm{Cu}(\mathrm{pabh})\left(\mathrm{O}_{2} \mathrm{CCH}_{3}\right)$ and $\mathrm{Cu}(\mathrm{pamh})\left(\mathrm{O}_{2} \mathrm{CCH}_{3}\right)$ display $\mathrm{Cu}(\mathrm{II}) / \mathrm{Cu}(\mathrm{I})$ reductions at -0.29 and $-0.22 \mathrm{~V}$, respectively and those of $\mathrm{Cu}$ (pabh)Cl and $\mathrm{Cu}$ (pamh)Cl display the reductions at -0.07 and $-0.06 \mathrm{~V}$ ( $\mathrm{vs} \mathrm{Ag} / \mathrm{AgCl}$ ), respectively. Considering the higher basicity of acetate-O compared to that of chloride the more anodic potentials observed for the chloride containing complexes is not surprising.

X-ray crystal structures of all the four complexes have been determined. In each complex, the planar tridentate monoanionic ligand coordinates the metal ion via the pyridine- $\mathrm{N}$, the imine- $\mathrm{N}$ and the amide- $\mathrm{O}$ atom of the deprotonated amide functionality. The fourth site is occupied by the acetate-O or chloride to form a square-plane around the metal centre.

In the solid state, both $\mathrm{Cu}(\mathrm{pabh})\left(\mathrm{O}_{2} \mathrm{CCH}_{3}\right)$ and $\mathrm{Cu}(\mathrm{pamh})\left(\mathrm{O}_{2} \mathrm{CCH}_{3}\right)$ exist as centrosymmetric dimeric species with the acetate groups acting as monoatomic equatorial-apical bridges ${ }^{16}$. Thus the metal centres of $\left[\mathrm{Cu}_{2}\left(\mu_{-} \mathrm{O}_{2} \mathrm{CCH}_{3}\right)_{2} \mathrm{~L}_{2}\right]$ are in 
distorted square-pyramidal $\mathrm{N}_{2} \mathrm{O}_{3}$ coordination spheres. For both complexes the bond parameters in the $\mathrm{O}, \mathrm{N}, \mathrm{N}, \mathrm{O}$ basal plane are unexceptional. The $\mathrm{Cu}-\mathrm{O}$ (apical) distance is relatively larger $(2 \cdot 284 \AA)$ and the $\mathrm{Cu}$-atom is displaced towards the apical bridging acetate $\mathrm{O}$-atom by $\sim 0 \cdot 1 \AA$. The $\mathrm{Cu} \cdots \mathrm{Cu}$ distances are identical in both complexes. These are: $3 \cdot 273(2) \AA\left(\mathrm{L}^{-}=\mathrm{pabh}^{-}\right)$and $3 \cdot 273(1) \AA\left(\mathrm{L}^{-}=\mathrm{pamh}^{-}\right)$. The $\mathrm{Cu}-\mathrm{O}-\mathrm{Cu}$ bridge angles are: $101 \cdot 4(2)^{\circ}\left(\mathrm{L}^{-}=\mathrm{pabh}^{-}\right)$and $101.94(15)^{\circ}\left(\mathrm{L}^{-}=\mathrm{pamh}^{-}\right)$.

An interesting observation in the structures of these two diacetato bridged complexes is the distances between the uncoordinated acetate $\mathrm{O}$-atoms and the azomethine $(-\mathrm{HC}=\mathrm{N}-)$ carbon atoms of the adjacent dimers. These O...C distances are 3.162(10) $\AA$ and $3 \cdot 199(6) \AA$ for $\left[\mathrm{Cu}_{2}\left(\boldsymbol{\mu} \mathrm{O}_{2} \mathrm{CCH}_{3}\right)_{2}(\mathrm{pabh})_{2}\right]$ and $\left[\mathrm{Cu}_{2}\left(\boldsymbol{\mu} \mathrm{O}_{2} \mathrm{CCH}_{3}\right)_{2}(\text { pamh })_{2}\right]$, respectively. The corresponding $\mathrm{C}-\mathrm{H} \cdots \mathrm{O}$ angles are 140.2 and $142.9^{\circ}$. Thus in each case, a onedimensional assembly of the dinuclear molecule is formed by the involvement of the molecule in two pairs of reciprocal $\mathrm{C}-\mathrm{H} \cdots \mathrm{O}$ interactions with its two neighbours on both sides (figure 6). The interdimer $\mathrm{Cu} \cdots \mathrm{Cu}$ distances for $\left[\mathrm{Cu}_{2}\left(\boldsymbol{\mu}_{2} \mathrm{O}_{2} \mathrm{CCH}_{3}\right)_{2}(\mathrm{pabh})_{2}\right]$ and $\left[\mathrm{Cu}_{2}\left(\boldsymbol{\mu} \mathrm{O}_{2} \mathrm{CCH}_{3}\right)_{2}(\text { pamh })_{2}\right]$ are 5.818(3) and 5.652(2) $\AA$, respectively.

In the solid state, magnetic moment (per $\mathrm{Cu}$ ) of each of these two acetato bridged complexes at $300 \mathrm{~K}$ is $\sim 1.9 \mu_{B}$. On cooling (up to $17 \mathrm{~K}$ ), no significant change in the magnetic moments is observed for both complexes. Linear relationships of the inverse magnetic susceptibilities with temperature clearly indicate that both complexes behave as Curie paramagnets (figure 7). The Curie $(C)$ and Weiss $(\theta)$ constants obtained by fitting the data using the expression for Curie-Weiss law are 0.45 and $-1.41 \mathrm{~K}$ and 0.46 and $-1.04 \mathrm{~K}$ for the complexes of $\mathrm{pabh}^{-}$and $\mathrm{pamh}^{-}$, respectively. Very small spin coupling constants $J\left(-1.54\right.$ to $\left.+0.63 \mathrm{~cm}^{-1}\right)$ have been reported for other similar acetato bridged dicopper(II) complexes ${ }^{16,17}$. The small values of $\boldsymbol{\theta}$ observed for the present complexes suggest a similar situation in these two complexes.

X-ray structures show that in each of the two chloride containing complexes, the metal centre is in a distorted square-pyramidal $\mathrm{N}_{2} \mathrm{OCl}_{2}$ coordination sphere (figure 8). As is the case with the acetate containing complexes described above, $\mathrm{Cu}(\mathrm{pabh}) \mathrm{Cl}$ is also a centrosymmetric equatorial-apical dichloro bridged dinuclear species (figure 8a). However, $\mathrm{Cu}($ pamh $) \mathrm{Cl}$ exists as polymeric chain species via equatorial-apical chloride bridges (figure $8 \mathrm{~b})^{16}$. The bond parameters in the $\mathrm{N}, \mathrm{N}, \mathrm{O}, \mathrm{Cl}$ basal plane are unexceptional for a copper(II) species. Like most square-pyramidal species, the metal centre is displaced towards the apical $\mathrm{Cl}$-atom by $0.23 \AA$ in the dimeric complex and by $0.13 \AA$ in the polymeric complex. The $\mathrm{Cu}-\mathrm{Cl}($ apical) distance $(2 \cdot 6682(10) \AA)$ in the dimeric

(a)

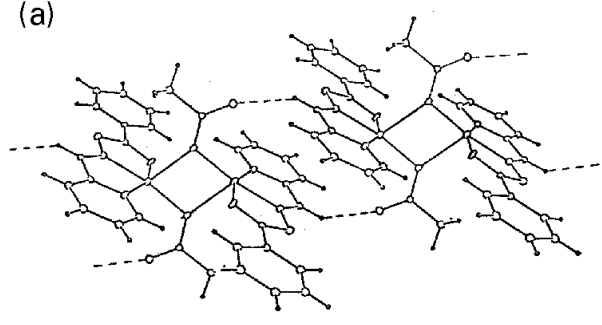

(b)

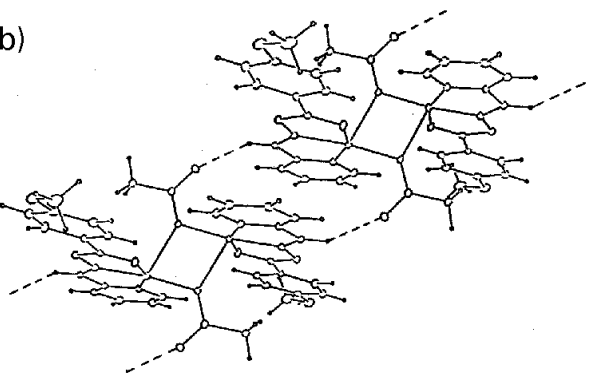

Figure 6. One-dimensional ordering of (a) $\left[\mathrm{Cu}_{2}\left(\mu-\mathrm{O}_{2} \mathrm{CCH}_{3}\right)_{2}(\text { pabh })_{2}\right]$, and (b) $\left[\mathrm{Cu}_{2}\left(\mu-\mathrm{O}_{2} \mathrm{CCH}_{3}\right)_{2}(\text { pamh })_{2}\right]$ via $\mathrm{C}-\mathrm{H} \cdots \mathrm{O}$ interactions. 


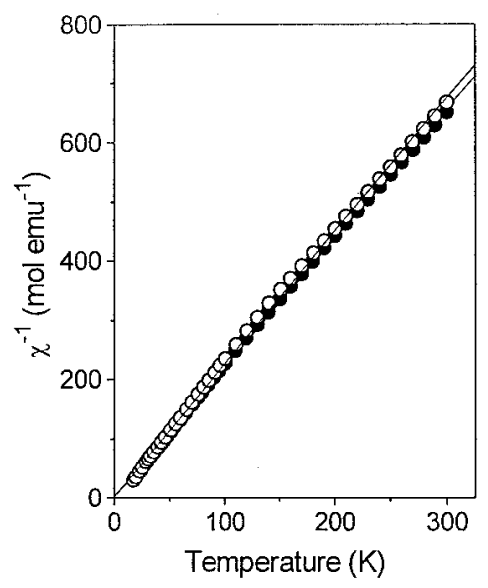

Figure 7. Temperature dependence of inverse magnetic susceptibilities (per monomer) for $\left[\mathrm{Cu}_{2}\left(\mu-\mathrm{O}_{2} \mathrm{CCH}_{3}\right)_{2}(\mathrm{pabh})_{2}\right](\mathrm{O})$ and $\left[\mathrm{Cu}_{2}\left(\mu-\mathrm{O}_{2} \mathrm{CCH}_{3}\right)_{2}(\mathrm{pamh})_{2}\right](\bullet)$. The solid lines represent the Curie-Weiss law fits.

(a)

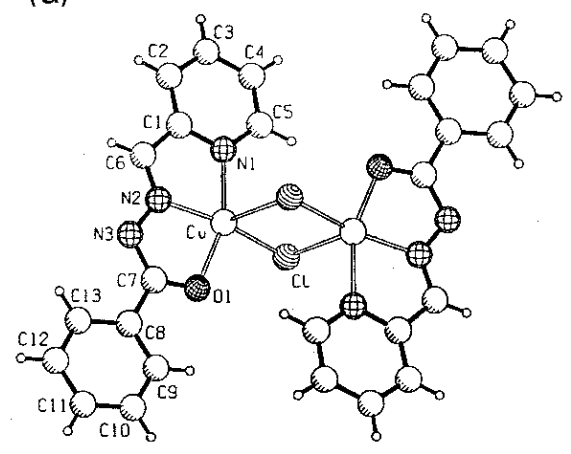

(b)

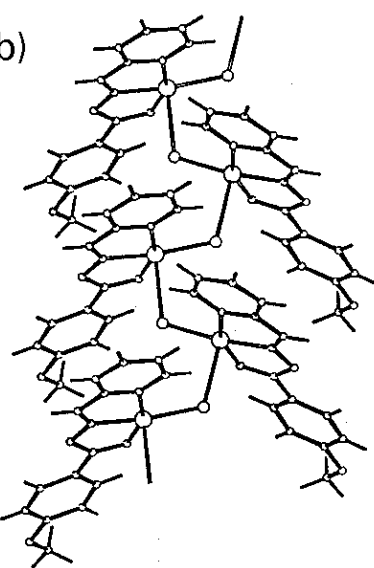

Figure 8. (a) Molecular structure of $\left[\mathrm{Cu}_{2}(\mu-\mathrm{Cl})_{2}(\mathrm{pabh})_{2}\right]$ with the atom labelling scheme. (b) Single chloride bridged one-dimensional structure of $[\mathrm{Cu}(\mathrm{pamh}) \mathrm{Cl}]_{n}$.

complex is noticeably shorter than that $(2.7821(13) \AA)$ in the polymeric species. The $\mathrm{Cu} \cdots \mathrm{Cu}$ distances and the $\mathrm{Cu}-\mathrm{Cl}-\mathrm{Cu}$ bridge angles are $3 \cdot 3918(9) \AA$ and $8689(3)^{\circ}$ and $4 \cdot 2866(7) \AA$ and $117 \cdot 60(5)^{\circ}$ for the dimeric and polymeric species, respectively.

Variable temperature magnetic susceptibility data indicate the Curie paramagnetic behaviour for both $\left[\mathrm{Cu}_{2}(\mu \mathrm{\mu l})_{2}(\mathrm{pabh})_{2}\right]$ and $[\mathrm{Cu}(\mathrm{pamh}) \mathrm{Cl}]_{n}$. The $C$ and $\boldsymbol{\theta}$ values obtained by linear least-squares fits of the data are 0.45 and $-3.57 \mathrm{~K}$ and 0.42 and $1.98 \mathrm{~K}$ for $\left[\mathrm{Cu}_{2}(\boldsymbol{\mu} \mathrm{Cl})_{2}(\mathrm{pabh})_{2}\right]$ and $[\mathrm{Cu}(\mathrm{pamh}) \mathrm{Cl}]_{n}$ respectively. Magnetostructural correlations for equatorial-apical dichloro bridged copper(II) dimeric complexes have been reported earlier ${ }^{18}$. The spin-exchange coupling constant $J$ in this type of complexes have been found in the range $-41 \cdot 3$ to $+6 \mathrm{~cm}^{-1}$. An empirical relationship has been established with the extent of spin-spin interaction and the ratio $\phi / R$ (where $\phi$ is the $\mathrm{Cu}-\mathrm{Cl}-\mathrm{Cu}$ bridge 
angle and $R$ is the $\mathrm{Cu}-\mathrm{Cl}$ (apical) distance). As this ratio increases, the value of $-2 J$ decreases and reaches a minimum and then again increases. For the complexes having $\phi / R \approx 33$ the value of $J$ is minimal. The paramagnetic behaviour of $\left[\mathrm{Cu}_{2}(\boldsymbol{\mu}-\mathrm{Cl})_{2}(\mathrm{pabh})_{2}\right]$ is consistent with the value (32.6) of $\phi / R$ in this complex.

Cryomagnetic behaviour of very few single chloride bridged polymeric copper(II) complexes are reported ${ }^{19}$. The intrachain magnetic interaction is very weak. The value of $J$ is in the range -6.1 to $1.58 \mathrm{~cm}^{-1}$. However, a trend in the $\mathrm{Cu}-\mathrm{Cl}-\mathrm{Cu}$ bridge angle $(\phi)$ and the coupling constant $J$ has been observed ${ }^{19}$. The value of $J$ is negative $\left(-6 \cdot 1 \mathrm{~cm}^{-1}\right)$ for large $\phi\left(144 \cdot 6^{\circ}\right)$. On the other hand, species with small $\phi$ display a weak ferromagnetic character $\left(\phi=128.1^{\circ}, \quad J=0.48 \mathrm{~cm}^{-1} ; \quad \phi=113.58^{\circ}, \quad J=1.58 \mathrm{~cm}^{-1}\right)$. The small but positive Weiss constant $(1.98 \mathrm{~K})$ observed for $[\mathrm{Cu}(\text { pamh }) \mathrm{Cl}]_{n}$ suggests an essentially paramagnetic character of the complex. However, it is interesting to note that $\phi\left(117.60(5)^{\circ}\right)$ in $[\mathrm{Cu}(\mathrm{pamh}) \mathrm{Cl}]_{n}$ is intermediate of the two $\phi$ values in those weakly ferromagnetic species.

\subsection{Copper(II) assisted transformation of azomethine to imidate}

Anticipating that a better electron releasing group such as $-\mathrm{NMe}_{2}$ at the para position of the aroyl fragment of II may help in obtaining a deprotonated amide-O bridged dicopper(II) species, reaction of $\mathrm{Cu}\left(\mathrm{O}_{2} \mathrm{CCH}_{3}\right)_{2} \cdot \mathrm{H}_{2} \mathrm{O}$ and $\mathrm{Hpadh}$ (1:1 mole ratio) in methanol has been conducted. X-ray crystal structure determination of the isolated product reveals that instead of the desired dicopper(II) complex, a centrosymmetric dimeric diacetato bridged complex has been produced. As in the case of acetate containing complexes described in the previous section, the acetate groups act as monoatomic equatorial-apical bridges between the copper(II) centres in this complex. However, the azomethine group $(-\mathrm{HC}=\mathrm{N}-)$ of $\mathrm{Hpadh}$ is transformed to imidate $(-(\mathrm{OMe}) \mathrm{C}=\mathrm{N}-)$ in the complexed ligand $\left(\mathrm{padh}^{\prime}\right)^{20}$. The molecular structure $\left[\mathrm{Cu}_{2}(\mu \mathrm{t}\right.$ $\left.\left.\mathrm{O}_{2} \mathrm{CCH}_{3}\right)_{2}\left(\text { padh' }^{\prime}\right)_{2}\right]$ is depicted in figure 9a. The free Schiff base (Hpadh) has been prepared in methanol and can be recrystallized from the same solvent. The molecular structure of Hpadh determined by X-ray crystallography is shown in figure $9 \mathrm{~b}$. Thus it is clear that the azomethine to imidate transformation in Hpadh occurs only after

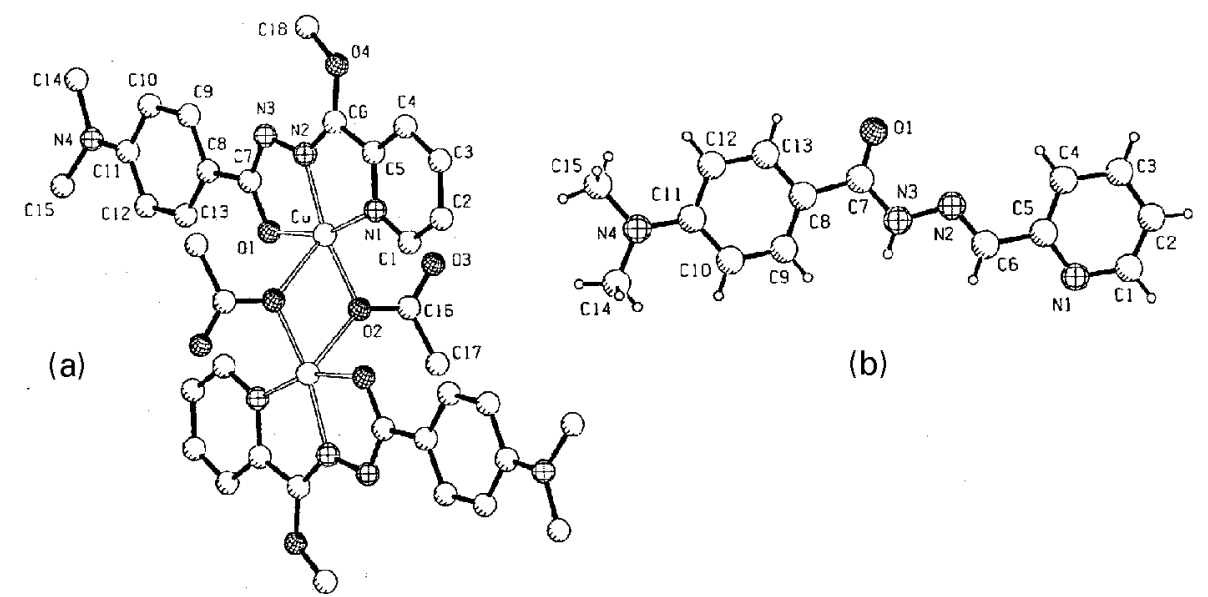

Figure 9. Molecular structures of (a) $\left[\mathrm{Cu}_{2}\left(\mu-\mathrm{O}_{2} \mathrm{CCH}_{3}\right)_{2}\left(\mathrm{padh}^{\prime}\right)_{2}\right]$ and (b) Hpadh. 


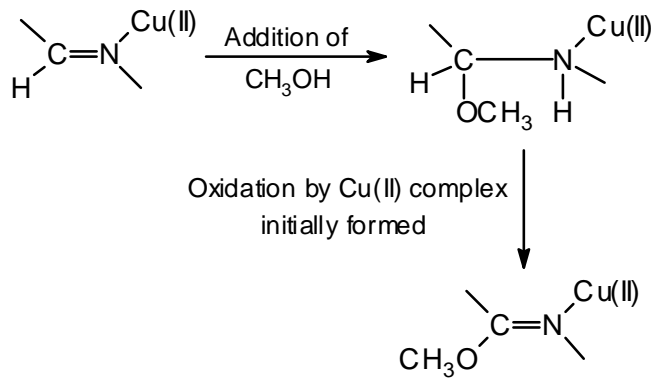

Scheme 1.

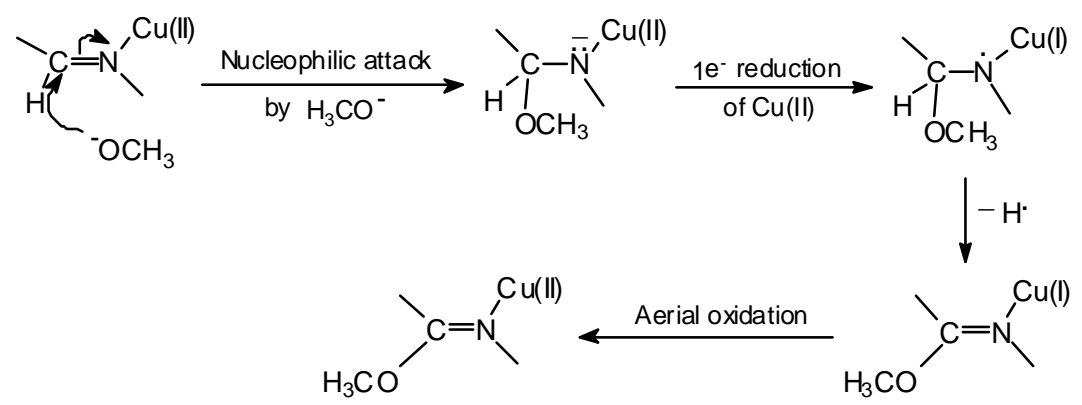

Scheme 2.

complexation with copper(II). It is expected that the azomethine group will be more polarized due to metal ion coordination to the imine-N. At least two pathways can be proposed for the observed transformation of the azomethine group. These are: (i) addition of methanol to the polarized azomethine moiety followed by oxidation to the isolated product $\left[\mathrm{Cu}_{2}\left(\boldsymbol{\mu}_{2} \mathrm{O}_{2} \mathrm{CCH}_{3}\right)_{2}\left(\mathrm{padh}^{\prime}\right)_{2}\right]$ by a portion of the copper(II) complex initially formed (scheme 1) and (ii) a nucleophilic attack at the polarized azomethine carbon by a methoxide followed by reduction of copper(II) to copper(I), homolytic cleavage of $(\mathrm{OMe}) \mathrm{C}-\mathrm{H}$ bond to form $(\mathrm{OMe}) \mathrm{C}=\mathrm{N}$ and finally oxidation of the metal ion from +1 state to +2 state by aerial oxygen (scheme 2 ). The low yield $(31 \%)$ of $\left[\mathrm{Cu}_{2}\left(\boldsymbol{\mu} \mathrm{H}_{2} \mathrm{CCH}_{3}\right)_{2}\right.$ $\left.\left(\text { padh }^{\prime}\right)_{2}\right]$ with respect to total copper taken during synthesis supports mechanism (i). Addition of water or alcohol to a metal coordinated azomethine group has been observed earlier $^{21}$. A mechanism similar to (i) has been suggested for the conversion of coordinated azomethine to amide in presence of water ${ }^{22}$.

\subsection{Self-assembly of $\left[\mathrm{Cu}(\mathrm{Hpadh}) \mathrm{Cl}_{2}\right]$ via hydrogen bonding and $\pi-\pi$ interaction}

The reaction of $\mathrm{Hpadh}, \mathrm{CuCl}_{2} \cdot 2 \mathrm{H}_{2} \mathrm{O}$ and $\mathrm{KOH}$ (1:1:1 mole ratio) in methanol has been performed expecting the isolation of a chloride containing complex analogous to that described in $\$ 4.2$. However, the amide functionality remains protonated in the isolated complex, $\left[\mathrm{Cu}(\mathrm{Hpadh}) \mathrm{Cl}_{2}\right]$. This possibly happens due to the lower acidity of the amide proton in Hpadh caused by the presence of the strong electron releasing $\mathrm{NMe}_{2}$ group at the para position of the aroyl fragment. The same complex has been isolated from methanolic medium in good yield $(72 \%)$ by reacting $\mathrm{Hpadh}$ and $\mathrm{CuCl}_{2} \cdot 2 \mathrm{H}_{2} \mathrm{O}$ in absence 
of $\mathrm{KOH}$. The bond parameters obtained from the X-ray crystal structure determination and all other physical properties are consistent with the protonated amide functionality and the +2 oxidation state of the metal ion in this complex ${ }^{23}$. The molecule has a squarepyramidal structure. The planar tridentate Hpadh coordinating through the pyridine-N,

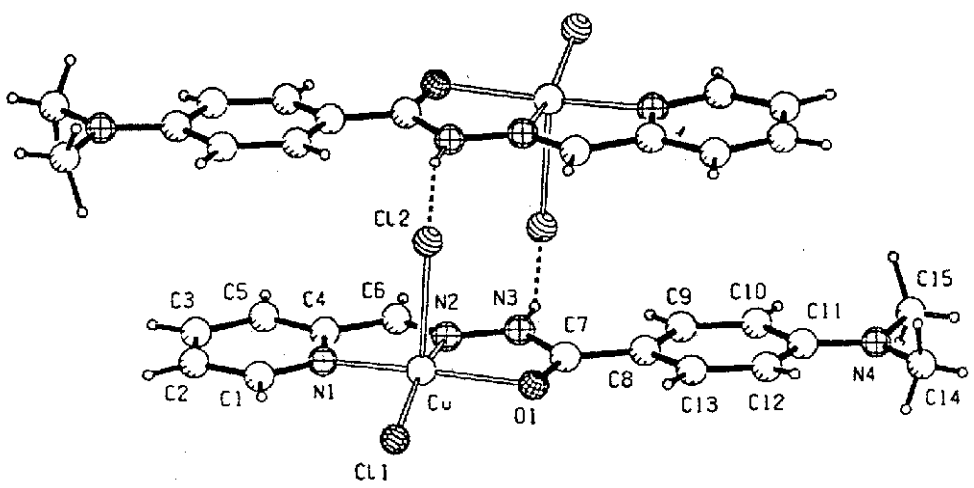

Figure 10. Hydrogen bonded dimeric arrangement of $\left[\mathrm{Cu}(\mathrm{Hpadh}) \mathrm{Cl}_{2}\right]$ molecules.
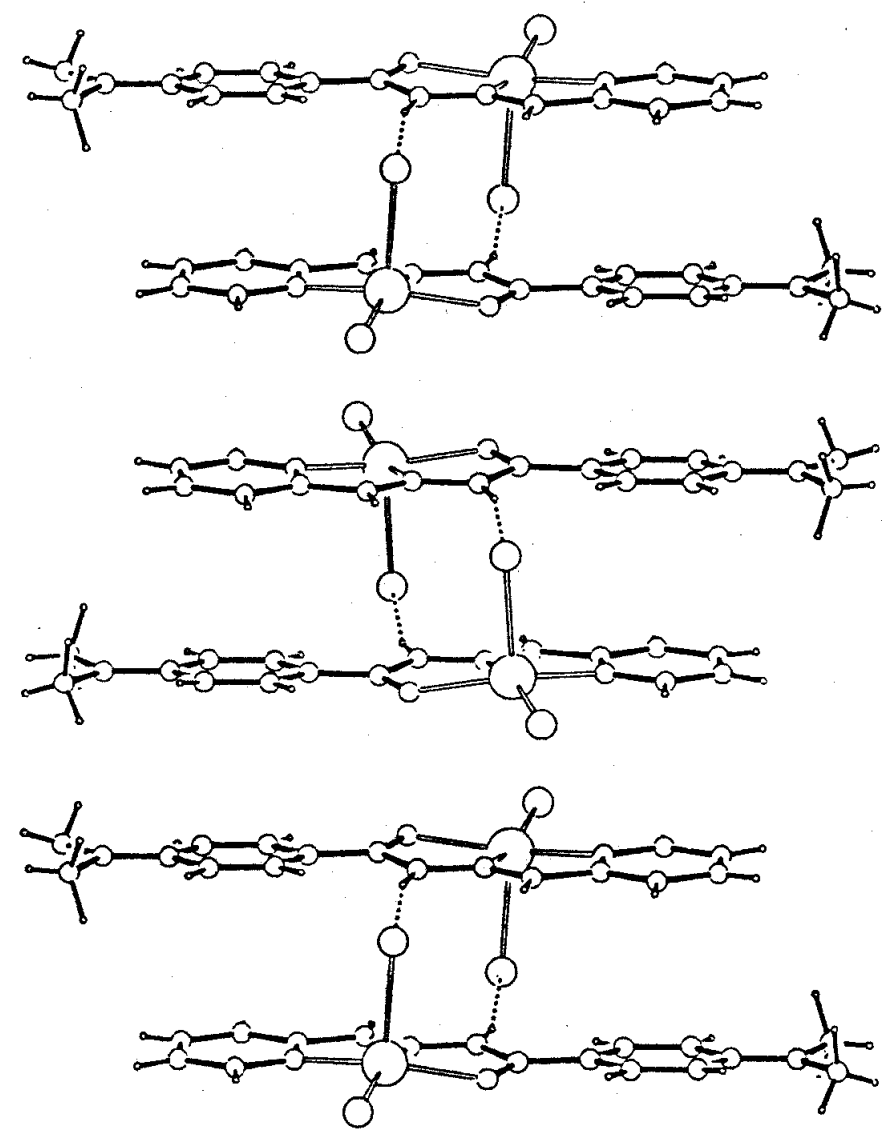

Figure 11. One-dimensional assembly of $\left[\mathrm{Cu}(\mathrm{Hpadh}) \mathrm{Cl}_{2}\right]$ molecules through $\mathrm{N}-$ $\mathrm{H} \cdots \mathrm{Cl}$ hydrogen bonds and $\pi-\pi$ interactions. 
the imine- $\mathrm{N}$ and the amide- $\mathrm{O}$ and one of the two chloride ions form the square base. The remaining chloride occupies the apical site. The metal to coordinating atom distances in the basal plane are comparable with those observed for the other similar complexes described in the previous sections. The $\mathrm{Cu}-\mathrm{Cl}$ (apical) distance $(2 \cdot 5128(10) \AA)$ is significantly longer than the $\mathrm{Cu}-\mathrm{Cl}$ (equatorial) distance $(2 \cdot 2053(9) \AA)$. As observed in most square-pyramidal complexes, the copper atom is displaced by $0.274 \AA$ from the basal plane towards the apical chlorine in this complex. Two $\left[\mathrm{Cu}(\mathrm{Hpadh}) \mathrm{Cl}_{2}\right]$ molecules are involved in a pair of reciprocal hydrogen bonds between the amide hydrogen atoms and the apical chlorine atoms (figure 10). The $\mathrm{N} \cdots \mathrm{Cl}$ distance is $3.080 \AA$ and the $\mathrm{N}-\mathrm{H} \cdots \mathrm{Cl}$ angle is $162 \cdot 4^{\circ}$. In this hydrogen bonded dimeric unit, the $\mathrm{Cu} \cdots \mathrm{Cu}$ distance is $6.455 \AA$. The ligand aromatic rings of $\left[\mathrm{Cu}(\mathrm{Hpadh}) \mathrm{Cl}_{2}\right]$ units in each hydrogen bonded dimer are involved in $\pi \pi$ interactions with the aromatic rings of adjacent dimers. The interplanar distances between the overlapping aroyl moiety rings and the pyridine rings are 3.578 and $3.534 \AA$, respectively. The corresponding centroid-to-centroid distances are 3.754 and $4 \cdot 246 \AA$, respectively. Thus the pyridine rings are more slipped compared to the aroyl benzene rings. In the dimeric fragment formed by the $\pi \pi$ interactions, the $\mathrm{Cu} \cdots \mathrm{Cu}$ distance is $4.023 \AA$. Thus in the solid state, a one-dimensional assembly of $\left[\mathrm{Cu}(\mathrm{Hpadh}) \mathrm{Cl}_{2}\right]$ molecules with alternate long and short $\mathrm{Cu} \cdots \mathrm{Cu}$ distances is formed through sequential intermolecular $\mathrm{N}-\mathrm{H} \cdots \mathrm{Cl}$ hydrogen bonds and $\pi-\pi$ interactions (figure 11).

Due to the short $\mathrm{Cu} \cdots \mathrm{Cu}$ distance between the $\pi$-stacked hydrogen bonded dimers, we have attempted a detailed investigation of the magnetic behaviour of this complex. However, variable temperature magnetic susceptibility data collected by using a powdered sample of $\left[\mathrm{Cu}(\mathrm{Hpadh}) \mathrm{Cl}_{2}\right]_{n}$ suggest no significant spin-spin interaction between the metal ions. The data could be satisfactorily fit using the expression for the Curie-Weiss law. The Curie and Weiss constants obtained are 0.454(1) and -0.8(3) K, respectively.

\section{Concluding remarks}

We have explored the coordination chemistry of copper(II) with aroylhydrazones with a specific aim of synthesizing amide-O bridged dicopper(II) complexes. Although we were unable to isolate such a species, several interesting monomeric, dimeric and polymeric complexes could be synthesized in the course of our investigation. The influence of electronic nature of the ligand substituents on the subtle variation of the coordination geometry in hexacoordinated copper(II) complexes has been noted. A rare example of a copper(II) complex containing a unidentate bent acetonitrile has been characterized. Metal ion activated transformation of azomethine to imidate has been realised for the first time. In the solid state, weak intermolecular interactions such as $\mathrm{C}-\mathrm{H} \cdots \mathrm{O}$ and $\mathrm{N}-\mathrm{H} \cdots \mathrm{Cl}$ hydrogen bonding and $\pi-\pi$ interactions lead to interesting one-dimensional self-assembly of some of the complexes. At present, we are engaged in generating new supramolecular species of copper and other metal ion complexes with these Schiff bases and different ancillary ligands.

\section{Acknowledgements}

Financial support received from the Council of Scientific and Industrial Research, New Delhi is gratefully acknowledged. I am deeply indebted to my students and coworkers 
whose names appear in the references. X-ray crystallographic studies were performed at the National Single Crystal Diffractometer Facility, School of Chemistry, University of Hyderabad (funded by the Department of Science and Technology, New Delhi).

\section{References}

1. (a) Hodgson D J 1975 Prog. Inorg. Chem. 19 173; (b) Creutz C 1983 Prog. Inorg. Chem. 30 1; (c) Kahn O 1985 Angew. Chem., Int. Ed. Engl. 24834

2. (a) Zanello P, Tamburini S, Vigato P A and Mazzocchin G A 1987 Coord. Chem. Rev. 77 165; (b) Fenton D E 1983 Advances in inorganic and bio-organic mechanisms (ed.) A G Sykes (London: Academic Press) vol. 2, p. 187; (c) Fenton D E 1988 Metal clusters in proteins (ed.) L Que Jr (Washington, DC: ACS)

3. (a) Pal S N, Radhika K R and Pal S 2001 Z. Anorg. Allg. Chem. 627 1631; (b) Sangeetha N R and Pal S 2000 Bull. Chem. Soc. Jpn. 73 357; (c) Sangeetha N R and Pal S 1997 J. Coord. Chem. 42 157; (d) Lakshmi A V, Sangeetha N R and Pal S 1997 Indian J. Chem. A36 844; (e) Sangeetha N R, Pal C K, Ghosh P and Pal S 1996 J. Chem. Soc., Dalton Trans. 3293

4. Sinn E 1976 Inorg. Chem. 15358

5. (a) Biradar N S and Havinale B R 1976 Inorg. Chim. Acta 17 157; (b) Iskander M F,El-Aggan A M, Refaat L S and El Sayed L 1975 Inorg. Chim. Acta 14167

6. Sangeetha N R, Baradi K, Gupta R, Pal C K, Manivannan V and Pal S 1999 Polyhedron 18 1425

7. O'Connor C J 1982 Prog. Inorg. Chem. 29203

8. (a) Mandal S K, Thompson L K, Newlands M J, Gabe E J and Nag K 1990 Inorg. Chem. 29 1324; (b) Nag K 1990 Proc. Indian Acad. Sci. (Chem. Sci.) 102269

9. Hay P J, Thibeault J C and Hoffmann R 1975 J. Am. Chem. Soc. 974884

10. Sangeetha N R and Pal S 1999 J. Chem. Crystallogr. 29287

11. (a) Storhoff B N and Takats J 1977 Coord. Chem. Rev. 231 (b) Beatti I R, Jones P J, Howard J A K, Smart L E, Gilmore C J and Akitt J W 1979 J. Chem. Soc., Dalton Trans. 528; (c) Bombieri G, Benetollo F, Klahne E and Fischer R D 1983 J. Chem. Soc., Dalton Trans. 1115; (d) Blount J F, Freeman H C, Hemmerich P and Sigwart C 1969 Acta Crystallogr. B25 1518; (e) Gorter S and Veschoor G C 1976 Acta Crystallogr. B32 1704

12. Chebolu V, Whittle R R and Sen A 1985 Inorg. Chem. 243082

13. (a) Reinen D and Friebel C 1979 Struct. Bonding 37 1; (b) Hathaway B J 1984 Struct. Bonding 57 55; (c) Hitchman M A, Maasicant W, van der Plas J, Simmons C J and Stratemeier H 1999 J. Am. Chem. Soc. 1211488

14. (a) Storrier G D, Colbran S B and Craig D C 1997 J. Chem. Soc., Dalton Trans. 3011; (b) Folgado J V, Henke W, Allman R, Stratemeier H, Beltran-Porter D, Rojo T and Reinen D 1990 Inorg. Chem. 29 2035; (c) Blake A J, Lavery A J and Schroder M 1996 Acta Crystallogr. C52 37

15. Pal S N, Pushparaju J, Sangeetha N R and Pal S 2000 Transition Met. Chem. 25529

16. Sangeetha N R and Pal S 2000 Polyhedron 191593

17. Chiari B, Helms J J, Piovesana O, Tarantelli T and Zanazzi P F 1986 Inorg. Chem. 25870

18. (a) Rojo T, Arriortua M I, Ruiz J, Darriet J, Villeneuve G and Beltran-Porter D 1987 J. Chem. Soc., Dalton Trans. 285; (b) Marsh W E, Patel K C, Hatfield W E and Hodgson D J 1983 Inorg. Chem. 22511

19. Estes W E, Hatfield W E, van Ooijen J A C and Reedijk J 1980 J. Chem. Soc., Dalton Trans. 2121

20. Sangeetha N R, Pal S N and Pal S 2000 Polyhedron 192713

21. (a) Busch D H and Bailar J C Jr. 1956 J. Am. Chem. Soc. 78 1137; (b) Harris C M and McKenzie E D 1962 Nature (London) 196670

22. Menon M, Choudhury S, Pramanik A, Deb A K, Chandra S K, Bag N, Goswami S and Chakravorty A 1994 J. Chem. Soc., Chem. Commun. 57

23. Sangeetha N R, Pal S N, Anson C E, Powell A K and Pal S 2000 Inorg. Chem. Commun. 3415 